\title{
Nitrite and Nitric Oxide as Potential Diagnostic Markers in Acute Vascular Diseases
}

James H. Silver*

President, Silver Medical Inc., USA

\begin{abstract}
Measurement of nitric oxide (NO) or a suitable index marker such as nitrite could potentially be used in the diagnosis of various vascular diseases. Among its many functions, nitric oxide plays important roles in ischemia/ reperfusion injury. Nitrite has recently been found to generate nitric oxide under conditions of ischemia or hypoxia. Research into the biology of the nitrite anion may impact a wide range of vascular diseases, such as stroke, acute myocardial infarction, cardiac arrest, sepsis, or other diseases. As nitrite begins to be evaluated for its therapeutic impact on these diseases in clinical trials, it may be important to obtain frequent or continuous measurements of NO or nitrite levels in real time in order to optimize such therapies. In addition, if nitrite therapy becomes successful in these trials, it may become necessary to provide clinicians with tools to monitor the effect of such therapy in real time.

This review summarizes currently available methods for measuring nitric oxide and nitrite, along with the advantages and disadvantages of each, including a novel method for real-time, continuous measurement of plasma nitrite from blood. The specificity of such measurements can be optimized by evaluating the concentration, kinetics, and location of the signal, which will allow physicians to perform differential diagnoses. Finally, several examples of vascular diseases in which nitric oxide plays a significant role, and in which monitoring NO or an index marker in real time could potentially provide clinically important information, are discussed.
\end{abstract}

Keywords: Diagnostic biomarker; Nitric oxide; Nitrite; Ischemia; Plasma measurement

\section{Introduction}

Nitric oxide (NO) is a signaling molecule involved in numerous biological pathways, including multiple disease and injury processes involving ischemia, infection, and inflammation. The biological role of the NO molecule was discovered in the 1980's, and its discoverers, Robert Furchgott, Louis Ignarro and Ferid Murad, shared the 1998 Nobel Prize in Physiology or Medicine. A quick Medline search for "nitric oxide" will yield over 100,000 references, indicating its ubiquity and importance. NO is known to be a key molecule regulating arterial blood flow $[1,2]$, and there is a significant body of literature regarding therapeutic applications of $\mathrm{NO}$ and pharmaceutical agents for delivery of NO. One of the most notable examples of a therapeutic compound which acts to increase the signaling capacity of NO (by inhibiting the consumption of cyclic guanosine monophosphate (cGMP)) is sildenafil citrate (Viagra). Inhaled NO is used therapeutically for respiratory complications in premature infants. As a diagnostic, exhaled NO is used for monitoring patients with airway inflammation, particularly asthma, but is unable to assess vascular pathologies more distant from the lungs. There are a number of vascular pathologies where a clinical diagnostic monitor for $\mathrm{NO}$ or a suitable index for NO, would be of significant clinical benefit. Nitrite $\left(\mathrm{NO}_{2}^{-}\right)$is a widely accepted surrogate marker for nitric oxide [3,4]. In addition, nitrite has recently been shown to be a circulating storage pool for $\mathrm{NO}$, rapidly producing NO under ischemic conditions, with multiple potential therapeutic applications now under investigation. The ability to monitor nitrite levels in real time could prove important for the therapeutic use of nitrite. This review will focus primarily on the potential utility of monitoring plasma nitrite, which is under investigation as a therapeutic agent, and on the prognostic and diagnostic value of nitrite for various diseases.

\section{Nitric Oxide role in vascular biology}

$\mathrm{NO}$ is produced by the conversion of L-arginine to L-citrulline by one of three enzymes, the nitric oxide synthases (NOS's) including endothelial NOS (eNOS) neuronal NOS (nNOS) and inducible NOS (iNOS). The former two enzymes are referred to as constitutive NOS's, and are dependent on calcium ions for activity, while iNOS is calciumindependent. nNOS is predominantly expressed in neurons and muscle, whereas eNOS is predominantly expressed in endothelial cells, and iNOS is expressed by macrophages. A variety of cell types and tissues express these isoforms, with many tissues expressing more than one isoform [5]. There are 5 enzyme co-factors [1] for the NOS enzymes, including flavin adenine dinucleotide (FAD), flavin mononucleotide (FMN), heme, tetrahydrobiopterin $\left(\mathrm{BH}_{4}\right)$ and calmodulin, so $\mathrm{NO}$ is tightly regulated under normal physiological conditions. NOS proteins first bind to the cofactors FAD and FMN. The additions of $\mathrm{L}$-arginine, $\mathrm{BH} 4$ and heme allow the NOS protein to form dimers. eNOS and nNOS dimers formed this way are inactive, and depend on calmodulin binding stimulated by increases in intracellular calcium. In contrast, iNOS dimers bind calcium/calmodulin and are active even at low (resting intracellular) concentrations of calcium. Thus, nNOS and eNOS are activated by a transient increase in intracellular calcium concentration, whereas iNOS is activated at the level of transcription [5]. The different isoforms of NOS are found in a variety of cell types and tissues, including neuronal cells and vascular endothelial cells.

eNOS is of particular importance for cardiovascular physiology, as it maintains basal vascular tone through release of low levels of $\mathrm{NO}$

*Corresponding author: James H. Silver, President, Silver Medical Inc., USA Tel: 650-464-1759, E-mail: jimsilver@sbcglobal.net

Received July 01, 2011; Accepted August 01, 2011; Published September 20 , 2011

Citation: Silver JH (2011) Nitrite and Nitric Oxide as Potential Diagnostic Markers in Acute Vascular Diseases. J Neurol Neurophysiol S1. doi:10.4172/2155-9562. S1-005

Copyright: (c) 2011 Silver JH. This is an open-access article distributed under the terms of the Creative Commons Attribution License, which permits unrestricted use, distribution, and reproduction in any medium, provided the original author and source are credited. 
Citation: Silver JH (2011) Nitrite and Nitric Oxide as Potential Diagnostic Markers in Acute Vascular Diseases. J Neurol Neurophysiol S1. doi:10.4172/2155-9562.S1-005

[6]. NO generated by eNOS diffuses from the endothelium to smooth muscle cells where it binds to and activates soluble guanylate cyclase (sGC) resulting in increased levels of cyclic guanine monophosphate (cGMP) [7]. cGMP activates protein kinase $\mathrm{G}$ (PKG) causing relaxation of smooth muscle cells by opening $\mathrm{K}^{+}$channels and/or by reducing the sensitivity of the contractile machinery to $\mathrm{Ca}^{2+}[8,9]$. This pathway is considered the predominant mechanism for $\mathrm{NO}$-mediated dilation of cerebral arteries and arterioles. The regulation of eNOS is multifaceted. Calcium is an important regulator of eNOS, and many agonists activate eNOS by increasing intracellular $\mathrm{Ca}^{2+}[10]$. Calcium complexes with calmodulin and activates eNOS by displacing it from cav-1 [11]. Additionally, eNOS in cerebral arteries and arterioles appears to be directly regulated by heat shock protein (HSP90), serine/threonine phosphorylation, and tyrosine phosphorylation. HSP90 and eNOS co-localize within endothelial cells [12]. Geldanamycin, an inhibitor of HSP90, reduces cGMP levels and constricts cerebral arteries to a similar extent as NOS inhibition [12].

Nitric oxide production is altered in many pathological states. Endothelial cells, neurons, glia, and invading leukocytes all produce reactive oxygen species (ROS) such as superoxide anion $\left(\mathrm{O}_{2} \bullet^{-}\right)$and peroxynitrite $\left(\mathrm{ONOO}^{-}\right)$which can scavenge $\mathrm{NO}$, cause endothelial dysfunction, and alter vascular tone [13]. Ironically, under conditions of limited substrate availability, the conversion of L-arginine to L-citrulline by eNOS can become uncoupled from NO production, resulting in the production of superoxide anion instead of NO [14]. Oxidative stress due to formation of reactive species mediates the damage secondary to both brain trauma and ischemia/reperfusion injury [15-17].

Recently, an alternative pathway for generation of NO has been discovered [18]. The anion nitrite was previously considered physiologically inert, a stable end product of nitric oxide (NO) metabolism, and a biomarker for NO activity. Nitrite has been shown to be a circulating storage pool for NO $[18,19]$ that the body can rapidly activate when needed. Rapid conversion of nitrite to NO can occur under ischemic conditions (low $\mathrm{pH}$, low partial pressure of oxygen $\left.\left(\mathrm{pO}_{2}\right)\right)$ [20]. There are several enzymes which may act to reduce nitrite to NO, including deoxyhemoglobin, deoxymyoglobin, xanthine oxoreductase (XOR), neuroglobin, eNOS, and components of the mitochondrial electron transport chain [22]. The deoxygenated state of hemoglobin has now been characterized as an allosterically regulated nitrite reductase. The different nitrite reductase "enzyme" systems operate along a range of physiological and pathological hypoxia, with hemoglobin reducing nitrite at an oxygen tension from $60 \mathrm{~mm} \mathrm{Hg}$ down to $20 \mathrm{~mm} \mathrm{Hg}$, myoglobin active below $4 \mathrm{~mm} \mathrm{Hg}$, and xanthine oxoreductase and acidic reduction reducing nitrite at zero oxygen and low $\mathrm{pH}[21,22]$. This allows for graded nitrite reduction to NO along the circulating and metabolic oxygen gradient [23]. In addition, as $\mathrm{pH}$ decreases, the rate of the reaction increases [24]. Maximal physiological dilatation via this mechanism is proposed to occur at around $50 \%$ hemoglobin oxygen saturation $\left(\mathrm{HbO}_{2}\right.$ sat (\%))[25]. Conversion of nitrite to NO by deoxyhemoglobin can occur in as little as 30 seconds to several minutes [26].

NO generated by NOS during normoxia may be chemically stored in a nitrite reservoir and re-generated during hypoxia and ischemia when oxygen-dependent NOS function is limited, and in areas in which increased blood flow would be desirable [27,28]. Nitrite represents the largest known source of bioavailable NO in the circulation, and can be considered an ischemic NO reservoir. There is an oxygendependent balance between NO and nitrite centered on hemoglobin in red blood cells. Nitrite ions produced in plasma from oxidation of intravascular NO by ceruloplasmin can be taken up by erythrocytes. Nitrite uptake into RBCs involves both diffusion of protonated nitrite $\left(\mathrm{HNO}_{2}\right)$ and facilitated diffusion of $\mathrm{NO}_{2}^{-}$via anion-exchanger-1 (AE1) [29]. Following its entry into the RBCs, nitrite reacts with oxy- and deoxyhemoglobin and undergoes oxidative and reductive reactions. As hemoglobin within erythrocytes becomes deoxygenated, intracellular nitrite may be catalytically reduced to $\mathrm{NO}$, which may then be released from the cell. In the presence of oxyhemoglobin, intraerythrocytic nitrite, which constitutes the majority of intravascular nitrite, reacts to produce methemoglobin and nitrate. NO in plasma is largely destroyed by reaction with trace amounts of plasma hemoglobin or may diffuse into erythrocytes to react with oxyhemoglobin to produce nitrate and methemoglobin. When NO reacts with deoxyhemoglobin, it produces primarily iron-nitrosyl-hemoglobin (NO-Hb) [2].

Nitrite is found in both plasma and erythrocytes, and there is an arterial to venous gradient in the nitrite levels in plasma, erythrocytes, and whole blood [30,31]. Nitrite levels decrease with blood deoxygenation from artery to vein, consistent with a dynamic oxygendependent nitrite metabolism. Nitrite gradients have been taken to signify arterio-venous nitrite consumption eliciting vasodilatation. However, these gradients may also reflect the difference between nitrite production due to NOS activity, where the arterial contribution is greater, and nitrite consumption due to nitrite reductase activity, where the venous contribution is greater [25]. Nitrite has become widely accepted as a marker of nitric oxide, since there is an artery-tovein gradient [3], indicating the consumption of the molecule during exercise stress in the forearm circulation, but other molecules such as $\mathrm{NO}_{3}{ }^{-}$and $\mathrm{SNO}-\mathrm{Hb}$ are not consumed. Gladwin et al. [32] reported that when humans were exposed to $80 \mathrm{ppm}$ inhaled NO gas, there was an increase in peripheral forearm blood flow that was only associated with increases in plasma nitrite. However, in many studies investigators report only combined values for nitrite $\left(\mathrm{NO}_{2}^{-}\right)$and nitrate $\left(\mathrm{NO}_{3}^{-}\right)$ (together commonly referred to as $\mathrm{NO}_{\mathrm{x}}$ ). Given the utility of nitrite as a marker for $\mathrm{NO}$, this can sometimes make interpretation of results difficult.

Plasma nitrite concentrations vary little between different mammals, indicating that the formation of nitrite is a common feature within the circulation preserved throughout evolution. In mammalian physiology, three sources of nitrite have been identified. The first significant source is dietary nitrite ingested from food. The second source is nitrite released during the reduction of dietary nitrate $\left(\mathrm{NO}_{3}^{-}\right)$. Considerable quantities of nitrate are contained in nitrate-rich vegetables such as beetroot, spinach, or dark green leafy vegetables [33]. Nitrate reductase enzymes are found in commensal bacteria in the mouth or intestines [33]. Such bacterial nitrate reductases contribute significantly to the endogenous nitrite pool of the host organism. There is some disagreement about the predominance of either dietary sources of nitrite or endogenous nitrite produced by ceruloplasmin-dependent oxidation of intravascular NO produced by eNOS [34]. Measured nitrite levels in whole blood or plasma show significant variability due to differences in dietary habits, lifestyle (e.g. tobacco consumption) and physical exercise prior to testing. Other investigators report that in humans and other mammals, $\sim 90 \%$ of the circulating plasma nitrite is derived from eNOS. In fasting humans, almost all nitrite in the vascular circulation originates from NO released by nitric oxide synthases (NOS) [2]. Plasma nitrite levels are reduced up to $70 \%$ in eNOS knockout mice and upon acute NOS inhibition in wild-type mice. Plasma nitrite reflects a constant proportion of the total NO synthesis and is now widely accepted as an index of NOS activity in vivo [35]. 
Citation: Silver JH (2011) Nitrite and Nitric Oxide as Potential Diagnostic Markers in Acute Vascular Diseases. J Neurol Neurophysiol S1. doi:10.4172/2155-9562.S1-005

Whole blood nitrite levels are similar at 2 or 4-hour intervals under fasting and non-fasting conditions, and are similar when drawn on 3 consecutive days with a coefficient of variation of $<8 \%$ [2,35]. In resting humans, various values for plasma nitrite and nitrate concentrations have been reported, ranging from $0.1-0.5 \mu \mathrm{M}$ for nitrite and $12-50 \mu \mathrm{M}$ for plasma nitrate. In one study, the nitrite levels measured in plasma, red blood cells (RBCs) and whole blood, of 15 healthy volunteers were $121 \pm 9,288 \pm 47,176 \pm 17 \mathrm{nM}$ respectively [2]. Nitrite in erythrocytes constitutes about two thirds of intravascular nitrite at concentrations approaching $300 \mathrm{nM}$ [2]. Virtually all nitrite (94 $\pm 4 \%)$ in erythrocytes is located in the cytosol [2]. Nitrite levels detected in blood are normally $<1 \mu \mathrm{M}$. However, the nitrite levels in the tissues are much higher, up to $10 \mu \mathrm{M}[36]$.

\section{Prognostic value of plasma nitrite}

In a study of plasma nitrite levels as a prognostic indicator of cardiovascular risk, nitrite levels decreased with increasing cardiovascular risk load. Studies [2,35] demonstrate that plasma nitrite can be determined with sufficient reproducibility in humans. Further, Kleinbongard et al. showed that plasma nitrite levels progressively decrease with increasing cardiovascular risk load, and that the presence of endothelial dysfunction and its degree are reflected by the relative difference in plasma nitrite compared to controls [35].

These studies suggest the possibility that plasma nitrite may indicate not only acute changes in NOS activity in animals and in healthy humans, but also chronic changes in NOS activity in individuals with early stages of atherosclerosis [35]. Because of great inter-individual variation in concentrations, nitrite seems to be less suitable for primary diagnostic purposes but may be a sensitive marker for the individual follow-up of disease states associated with changes in endothelial function. Thus, determination of plasma nitrite may be suitable to assess endothelial dysfunction in patients and to monitor the efficacy of therapeutic interventions in future clinical trials [35].

\section{Ischemia/reperfusion injury}

Ischemia-reperfusion (IR) injury is a series of cellular events that takes place following the resumption of oxygen delivery to a tissue after a period of hypoxia. This injury may be severe enough to cause significant morbidity and mortality [37]. In the 1980's, it was discovered that a series of short-duration ischemic events in advance of a longer-duration ischemic insult could confer significant protection. Preconditioning by ischemic tolerance was first identified in the heart, and was subsequently found to occur in the brain and a variety of organs including the liver, intestine, kidney, and lung [38]. Preconditioning stimuli include ischemia, low doses of endotoxin, hypoxia, hypothermia and hyperthermia, cortical spreading depression, anesthetics, and 3-nitropropionic acid, among others. Preconditioning strategies have always proven to be effective in experimental models but the clinical relevance of such strategies is questionable. While it would be clinically dangerous and impractical to precondition at-risk patients with ischemia [38], an understanding of the protective mechanisms could lead to therapeutic approaches to improve patient outcomes.

Cardiac preconditioning requires a minimum of 2 minutes of ischemia and reperfusion to induce an immediate protective effect of ischemic preconditioning (IPC). IPC occurs in 2 phases: an "early" phase of protection, which develops within minutes after initial ischemia and lasts 2 to 3 hours, and a "late" phase of protection, which begins 12 to 24 hours later and lasts 3 to 4 days. Late IPC has protective effects against myocardial infarction and myocardial stunning, but early IPC only has an effect against myocardial infarction [39]. Ischemic preconditioning in the brain is accomplished globally by occlusion of the bilateral common carotid arteries, or focally by occlusion of one side of the middle cerebral artery for about 1 to 20 minutes. Preconditioning-induced neuroprotection is observed not only in terms of infarct volume but also in terms of neurological scores and behavior studies in animals [38].

A number of mechanisms have been advanced to explain the cytoprotective effects of NO following IR injury. A thorough discussion of NO-mediated cytoprotection against IR injury is beyond the scope of this review, so we refer the reader to recent reviews of the subject [40-42]. NO has been extensively studied in the setting of myocardial IR injury. A review of the literature which investigated the role of NO in modulating the severity of IR injury in the non-preconditioned myocardium spanning the period from 1991 to 2001 found that $73 \%$ of the studies reported that NO (endogenous or exogenous) was cardioprotective, whereas $12 \%$ reported that NO was detrimental [40]. This very comprehensive analysis revealed that the discrepancies between these two opposing findings can be explained by the dose of NO investigated, as it was found that physiological levels (i.e., nanomolar) of NO promote cytoprotection and suprapharmacological levels (i.e., high micromolar and millimolar) mediate cellular necrosis and apoptosis [4].

NO may play a key role as a mediator of the neuronal ischemic preconditioning response, either in conjunction with or independent of NMDA receptor activation [38,43]. Administration of the NOS inhibitor (N-nitro-L-arginine methyl ester (L-NAME)) before and during the preconditioning protocol attenuated functional recovery [44]. Treatment with the iNOS inhibitor aminoguanidine abolished the induced protection [38]. Exogenous NO was shown to elicit preconditioning-induced protection [44]. Scavenging of NO during preconditioning significantly attenuated the induced neuronal tolerance, and neither eNOS- nor nNOS-knockout mice showed protection following ischemic preconditioning. Pharmacological elevation in tissue cGMP levels by administration of NO donors S-nitroso-N-penicillamine (SNAP) or sodium nitroprusside (SNP) before sustained ischemia elicited cardioprotection similar to ischemic preconditioning [44]. Subsequent studies also emphasized the significance of cGMP and activation of PKG in the triggering of preconditioning [44]. Increases in the tissue cyclic nucleotides, cyclic adenosine monophosphate (cAMP) and cGMP were found to occur during a multi-cycle preconditioning protocol, suggesting roles for the beta-adrenergic signaling pathway and nitric oxide $(\mathrm{NO})$ as triggers of cardioprotection [44]. The administration of inhaled NO gas therapy also significantly protects the myocardium [45]. Preconditioning by volatile anesthetics also appears to involve NO pathways $[38,46]$.

NO possesses a number of physiological properties that makes it a potent cardioprotective signaling molecule. First, NO is a potent vasodilator in the ischemic myocardium [47] which allows for essential perfusion of injured tissue. Second, NO reversibly inhibits mitochondrial respiration [48]. The inhibition of mitochondrial respiration during early reperfusion leads to a decrease in mitochondrial-driven injury by extending the zone of adequate tissue cellular oxygenation away from vessels [49]. Third, NO is a potent inhibitor of neutrophil adherence to vascular endothelium [50]. Neutrophil adherence is an important event initiating further leukocyte activation and superoxide radical generation, which in turn leads to injury to the endothelium and perivascular myocardium. Fourth, NO prevents platelet aggregation, which together with the anti-neutrophil actions of NO attenuates 
Citation: Silver JH (2011) Nitrite and Nitric Oxide as Potential Diagnostic Markers in Acute Vascular Diseases. J Neurol Neurophysiol S1. doi:10.4172/2155-9562.S1-005

capillary plugging [51]. Finally, NO inhibits apoptosis [52] either directly or indirectly by inhibiting caspase-3-like activation via a cGMP-dependent mechanism and by direct inhibition of caspase-3like activity through protein S-nitrosylation [6].

\section{Nitrite therapy for IR injury}

Nitrite therapy has proven to be an effective preconditioning agent [21]. There are several limitations to the currently used NO-based therapies that preclude their widespread use, but which nitrite might address. Inhaled NO therapy and NO donor therapy have the potential to cause unwanted side effects, since both therapies rely on systemic delivery. For example, NONOates, a class of NO donors, release NO over a period of time depending on the half-life of the drug [4]. Since NO begins to be released as soon as the drug enters the blood stream, there is no way of ensuring that the NO is released only at the site of injury. As a result, higher concentrations of the drug have to be administered to achieve the desirable therapeutic effects. This in turn can result in unwanted systemic side effects, such as hypotension or NO-mediated cytotoxicity. Alternative means to effectively deliver NO to the site of injury are thus necessary to achieve the therapeutic potential of NO-based therapies [4].

Nitrite is a relatively stable molecule that can be transported in the circulation and stored in tissues. Nitrite releases NO under conditions that exist in injured tissue (ischemia, hypoxia, or low $\mathrm{pH}$ ), which allows nitrite to preferentially target injured tissue and reduce the risk of systemic hypotension and other unwanted side effects. This is probably the most important aspect of nitrite therapy [4]. In addition, since nitrite has been used for many years as part of the cyanide antidote kit in humans there is a wealth of clinical data to support the safety of very high doses of sodium nitrite in critically ill patients [4].

During hypoxia and ischemia, nitrite not only promotes blood flow by conversion to nitric oxide, it also protects the mitochondria [24]. Nitrite acts to inhibit mitochondrial respiration by blocking the electron transport chain at both complex I and cytochrome c. Under ischemic conditions, myoglobin reduces nitrite to NO, which can bind reversibly to the catalytic center of cytochrome c oxidase. Nitrite can also inhibit complex I by S-nitrosation [21]. Partial inhibition of mitochondrial respiration can regulate tissue oxygen gradients and conserve oxygen, particularly in conditions of physiological hypoxia. Inhibition of the most actively respiring mitochondria and those closest to the oxygen source would allow oxygen to diffuse beyond these mitochondria and further into the tissue to those sections of the tissue that are more distant from the oxygen source. This extension of the oxygen gradient deeper into the tissue would also extend the NO gradient in the tissue, thereby increasing the apparent bioavailability of both oxygen and $\mathrm{NO}$ [49]. While reperfusion of the tissue is necessary to restore cellular energetics, reperfusion itself exacerbates mitochondrial damage and tissue injury. Inhibition of complex I by nitrite is thought to contribute to cytoprotection by blocking entry of electrons into the respiratory chain and thus attenuating the burst of reactive oxygen species generation associated with reperfusion.

Nitrite has recently been found to confer cytoprotection against IR injury in a number of animal models [23]. Although the mechanisms of this phenomenon are still being characterized, the reproducibility of this effect in multiple animal IR models suggests nitrite as a novel potential therapy for human ischemic diseases [4].

\section{Current methods for measurement of $\mathrm{NO}$ and $\mathrm{NO}_{2}$}

Monitoring authentic NO is very challenging because this free radical has a half-life of only $\sim 1$ microsecond to 2 milliseconds in blood, and a diffusion distance of only about $0.1 \mu \mathrm{m}$ depending on model assumptions [34]. The measurement of NO metabolic products nitrite $\left(\mathrm{NO}_{2}^{-}\right)$and nitrate $\left(\mathrm{NO}_{3}^{-}\right)$, is less technically challenging than direct NO measurement. Table 1 provides a comparison of current methods for measuring $\mathrm{NO}$ and $\mathrm{NO}_{2}$. Other proposed indices for NO include nitrosohemoglobin [20] and nitrosated and nitrosylated proteins, such as SNO-albumin [53].

Non-invasive measurements of NO levels can be obtained using electron paramagnetic resonance (EPR) imaging to make real-time measurements by administration of spin-trapping agents. This technique is useful in either in vitro studies or in animal research, but human trials using EPR have yet to be reported (excluding analysis of blood samples extracted from patients). Although EPR is a very powerful imaging tool in NO research, the heavy instrumentation, high cost, small sample size, and the potential toxicity of the spin-trapping agents are major roadblocks for future clinical applications [54]. Magnetic resonance imaging (MRI) and positron emission tomography (PET) are also under investigation for monitoring changes in NO and NOS enzymes, respectively. The biggest disadvantage of MRI is its low sensitivity, requiring millimolar levels of $\mathrm{NO}$, which will mean that its applications will be very limited. In addition, there are major concerns about the potential toxicity of the imaging agents. Relatively long data acquisition times are typically needed to generate a detectable MR signal, while the lifetime of NO is short, so the accuracy of MRI measurements of NO is questionable [54]. PET imaging has only been evaluated to detect NOS enzyme expression, but has been unsuccessful to date. First, the expression of NOS is in the cytoplasm, and the radiolabeled NOS inhibitors may not permeate the cell membrane efficiently which dramatically reduces tracer uptake. Second, the specificity of these NOS inhibitors may not be high enough for imaging applications; many of them can undergo nonspecific adsorption to other proteins such as albumin. Third, the stability of those tracers in vivo is a major concern [54].

NO-specific electrodes are commercially available (e.g., World Precision Instruments, Innovative Instruments). Their potential clinical uses are limited because both oxygenated and deoxygenated hemoglobin compete with the sensor for NO. Recently, Takarada et al. [55] reported the first successful intravascular measurement of NO in humans using an NO electrode mounted onto a catheter. The sensor was positioned in the coronary sinus, and an acetylcholine stimulus was administered nearby in the left main coronary artery. The sensor could not measure the absolute level of circulating NO because of the differences between the calibration sites and the measuring site. There was a weak but significant correlation between the NO levels measured by the catheter-type NO sensor and the nitrite level from samples taken at the same time and in the same location, measured by HPLC with the Griess reaction $(r=0.41, p=0.048)$ [55]. The weakness of the correlation may be because the reported detection limit for nitrite was only $10 \mathrm{nM}$, about the same concentration as the largest response measured by the NO electrode. The weak correlation may also have been due to rapid oxidation of NO to nitrite, so that by the time the NO reached the sensor, much of it had already been converted to nitrite. The utility of a catheter with an NO sensor could be valuable in circumstances where it can be placed in close proximity to the stimulus. However, while the position of the NO source may be known in animal or in vitro studies, an NO-sensing catheter [56] may not be clinically useful in situations where the location of the NO source is not known in advance or is not safely reachable by the sensor, because NO has a short diffusion distance of $\sim 0.1 \mu \mathrm{m}$ [34]. 
Citation: Silver JH (2011) Nitrite and Nitric Oxide as Potential Diagnostic Markers in Acute Vascular Diseases. J Neurol Neurophysiol S1. doi:10.4172/2155-9562.S1-005

Use of a catheter-mounted sensor [56] requires fluoroscopic guidance, which is available in catheterization labs, but not typically in operating rooms or intensive care units. Intravascular use of NO electrodes for a prolonged period may also be limited by thrombosis. Most examples of NO electrodes in human use are limited to non-vascular applications, such as extracorporeal blood during hemodialysis [57], insertion into synovial fluid [58] and subcutaneous insertion into the forearm [59].

Monitoring exhaled NO is useful for applications involving airway inflammation such as asthma, but not for most other applications where NO from a distant source would convert to nitrite before it reached the lungs [60]. Exhaled NO has a very short half-life in the lung vasculature and should be incapable of distal transport in blood. This is because NO reacts in a nearly diffusion-limited reaction with both oxyhemoglobin (6 to $8 \times 10^{7} \mathrm{~mol} / \mathrm{L} / \mathrm{sec}$ ) and deoxyhemoglobin $\left(2\right.$ to $6 \times 10^{7} \mathrm{~mol} / \mathrm{L} /$ sec) to form methemoglobin/nitrate and iron nitrosyl hemoglobin, respectively, which yield a half-life of $\sim 1 \mu$ s and a diffusion distance of $\sim 0.1 \mu \mathrm{m}$ [34]. Monitoring nitrite using exhaled breath condensate (EBC) is another alternative [61], but analysis is complicated due to the substantial contribution of nitrite from the oropharyngeal tract during standard collection of EBC [62].

As mentioned above, nitrite $\left(\mathrm{NO}_{2}^{-}\right)$is a widely accepted surrogate marker for nitric oxide [3,4]. The circulating half-life of nitrite has been estimated to be from 11 to 42 minutes [34,63,64], but 5-8 hours for nitrate [65]. This decay of nitrite is dominated by the reaction with oxyhemoglobin to methemoglobin and nitrate. Thus, nitrite is an appropriate marker [66] because it is present long enough to be measured, yet changes rapidly enough to track variations in NO levels. Plasma nitrite levels closely track changes in whole blood nitrite and cardiac nitrite in a rat model of cardiac arrest [67].

A great deal of interest in the nitrite anion itself has recently emerged [32]. Given the tremendous research interest in this field, as well as the numerous potential clinical applications described below, it would be of considerable value to be able to monitor nitrite in blood in real time, on a continuous basis. This is because nitrite has a relatively short half-life, and sample preparation requires considerable care [63]. An issue with measuring $\mathrm{NO}_{\mathrm{x}}$ is the widespread contamination of labware with $\mathrm{NO}_{x}$ levels that can confound experimental results [53,63]. One of the most commonly reported methods for measuring $\mathrm{NO}_{2}^{-}$is ozonechemiluminescence [63]. However, along with other current methods including HPLC [68], gas chromatography-mass spectroscopy (GCMS) [28] and capillary electrophoresis [69], ozone-chemiluminescence requires multiple sample preparation steps that require specimens to be centrifuged, chemically stabilized, frozen and then transported to these instruments for later analysis, with results provided hours or days later, which does not provide a suitable response time for many clinical applications. The short half-life of nitrite in whole blood, demanding rapid separation of plasma from erythrocytes, is a considerable obstacle for plasma nitrite determination in clinical practice [2]. Methods such as ion-selective nitrite electrodes [70] are insufficiently sensitive to monitor $\mathrm{NO}_{2}^{-}$in the physiological regime (100 nM to $\left.1 \mu \mathrm{M}\right)$. While some investigators report a low detection limit for the Griess reaction combined with HPLC $(\sim 10 \mathrm{nM})$ [55] a summary of research performed with the Griess reaction showed many reports with a detection limit of $\sim 1 \mu \mathrm{M}$ [63]. GC-MS methods can also be insufficiently sensitive for measurement of nitrite in plasma and whole blood [28].

We have previously described a technology that can enable measurement of physiological levels of nitrite in blood plasma in humans in real time with no sample preparation and has the potential to enable clinical decision-making [71]. Figure 1 illustrates an early prototype of the plasma nitrite monitor. In this method, blood is processed through a small hemodialysis-type filter with a surface area of $20 \mathrm{~cm}^{2}$ and a molecular weight cutoff of $10 \mathrm{kD}$ to exclude hemoglobin. A transmembrane pressure gradient is applied between the inlet and outlet of the filter, resulting in separation of the blood elements by molecular weight. The filtrate containing the free nitrite is then pumped from the filter and mixed with a solution of dilute sulfuric acid and potassium iodide. This process stoichiometrically reduces the nitrite to nitric oxide [141]. The filtrate is then monitored for NO levels using an NO-specific electrode. A limitation of this technology is the requirement to draw blood samples. Currently about $30 \mathrm{ml}$ of blood are required for about 6 hours of monitoring, but this volume may be further reduced as the technology is improved. Because the blood is processed using clinically proven filter membranes, the potential exists to salvage the retentate, primarily erythrocytes, leukocytes, and larger proteins, for re-infusion into the patient. Figure 2 shows a calibration trace of nitrite in anticoagulated human blood from $100 \mathrm{nM}$ to $5 \mu \mathrm{M}$. The system shows a linear response $\left(r^{2}=0.99\right)$ over a nitrite concentration range from $10 \mathrm{nM}$ to $5 \mu \mathrm{M}$ in diluted blood (1 part blood to 4 parts normal saline) which surpasses the normal physiological

\begin{tabular}{|c|c|c|c|c|c|}
\hline Method & $\mathrm{NO} / \mathrm{NO}_{2}$ - Detection Limit* & $\begin{array}{l}\text { Continuous or } \\
\text { Discrete? }\end{array}$ & $\begin{array}{c}\text { Direct Measure in } \\
\text { Blood? }\end{array}$ & $\begin{array}{l}\text { Lab Sample Prep } \\
\text { Required? }\end{array}$ & $\begin{array}{l}\text { Potential as rapid } \\
\text { clinical diagnostic? }\end{array}$ \\
\hline EPR & $\sim 10 \mathrm{nM}[139]$ & Continuous & Yes & No & No \\
\hline MRI & $\sim 1 \mathrm{mM}[54]$ & Continuous & Yes & No & No \\
\hline Griess Reaction & $10-1500$ nM [63] & Discrete & No & Yes & No \\
\hline Ozone-Chemiluminescence & $1 \mathrm{nM}[63]$ & Discrete & No & Yes & No \\
\hline Ion-selective nitrite electrode & $0.5-10 \mu \mathrm{M}[70]$ & Continuous & Yes & No & Yes \\
\hline Nitric oxide electrode & 0.08-1 nM [55] & Continuous & Yes & No & Yes \\
\hline HPLC & 10 pM [68] & Discrete & No & Yes & No \\
\hline Capillary Electrophoresis & $60 \mathrm{nM}[69]$ & Discrete & No & Yes & No \\
\hline GC-MS & $0.5 \mu \mathrm{M}[28]$ & Discrete & No & Yes & No \\
\hline Exhaled NO & $0.5 \mathrm{ppb}(\sim 15 \mathrm{nM})[140]$ & Continuous & No & No & No \\
\hline Exhaled breath condensate & $\sim 1 \mu \mathrm{M}[61]$ & Continuous & No & No & No \\
\hline Silver Medical instrument & $<10 \mathrm{nM}[71]$ & Continuous & Yes & No & Yes \\
\hline
\end{tabular}

Table 1: Comparison of current $\mathrm{NO}$ and $\mathrm{NO}_{2}-$ detection methods. *Detection limits are approximate since these can vary in practice. 
Citation: Silver JH (2011) Nitrite and Nitric Oxide as Potential Diagnostic Markers in Acute Vascular Diseases. J Neurol Neurophysiol S1. doi:10.4172/2155-9562.S1-005

range (typically $100 \mathrm{nM}$ to $1 \mu \mathrm{M}$ ) [19]. The initial response time to a $100 \mathrm{nM}$ bolus of $\mathrm{NO}_{2}$ is 1-2 minutes. Analysis can be performed either continuously or with discrete samples. Any background signal from potential contaminants can simply be measured using nitrite-free water or saline, and then subtracted from the sample. Blood samples can be placed directly into the instrument, or drawn from the subject through an existing catheter.

\section{Specificity of $\mathrm{NO}$ or $\mathrm{NO}_{2}^{-}$as a biomarker}

Nitric oxide and $\mathrm{NO}_{2}^{-}$are involved in numerous biological pathways, therefore the specificity of these markers for vascular pathologies will be dependent upon concentrations, kinetics, and localization [27,72]. Interpretation of NO or nitrite readings will require a differential diagnosis. For example, the rate of increase in $\mathrm{NO}_{\mathrm{x}}$ levels generated by eNOS and/or nNOS (during ischemia) is from 10 to 50 times faster $[73,74]$ than the rate of $\mathrm{NO}_{\mathrm{x}}$ generated by iNOS (during inflammation) which provides one method to distinguish between ischemia and inflammation or infection. Continuous or frequent discrete measurement of $\mathrm{NO}$ or an index marker should thus allow distinction between ischemic events superimposed on inflammatory processes. Location-specific measurements will also help to improve marker specificity. There is an arterio-venous gradient in plasma $\mathrm{NO}_{2}{ }^{-}$levels, indicating that $\mathrm{NO}_{2}{ }^{-}$is not at a constant level in the general circulation. For example, measurement using a central venous catheter in the superior vena cava (SVC) will be primarily indicative of nitrite in the upper body, including the brain, head and arms, and may be differentiated from more global changes by comparison with measurements in the inferior vena cava or from an arterial line. Alternatively, measuring $\mathrm{NO}_{2}$ in the coronary sinus could be indicative of cardiac changes. Making measurements from multiple locations simultaneously would indicate if a particular organ was experiencing ischemia.

Several examples of the potential utility of monitoring plasma nitrite or nitric oxide in real time are discussed below, although there are numerous examples which are beyond the scope of this review, such as traumatic brain injury [75,76], cancer [77], or renal [78] or hepatic [37] ischemia-reperfusion injury, among many others.

\section{In-hospital stroke}

Stroke is the third leading cause of death in the US, behind heart disease and cancer, and is a leading cause of serious, longterm disability $[79,80]$. Out of 795,000 strokes each year, roughly 200,000 are fatal, and the five-year survival rate of non-fatal strokes is only $50 \%$ [81]. The estimated direct U.S cost of stroke for 2009 is $\$ 54.2$ billion with the long-term costs for an individual estimated to be $\$ 140,000$ [82]. Ischemic stroke accounts for approximately $87 \%$ of all strokes, while the remainder are hemorrhagic [81]. In over $60 \%$ of stroke patients, vascular thrombus deposition is responsible for the interruption of cerebral blood flow (CBF). Reduced CBF and severe oxygen deficiency leads to ischemia, and eventually to behavioral and functional deficits, morbidity and mortality [83,84]. Key factors in predicting stroke morbidity and mortality are severity and time to treatment, with earlier treatment equating with improved outcome. A landmark study documented that treatment within 60 minutes reduces disability by $30 \%$ [85]. Since stroke symptoms can be ambiguous and many patients are alone, sedated, in surgery, or asleep during stroke onset, delays in recognition and assessment are common [86], thus significantly limiting the ability to provide timely therapy.

Even in hospitals, where 6.5 to $15 \%$ of strokes occur, delayed detection, assessment, and treatment are common [87]. Common cardiac, vascular and intracranial surgical procedures have significant intra-operative stroke rates, yet patients are not adequately monitored. Nearly 750,000 such procedures are performed every year in the US, including 500,000 coronary artery bypass grafts (CABG), 130,000 carotid endarterectomies (CEA), and 100,000 heart valve replacements. The risk of intraprocedural stroke due to $\mathrm{CABG}$ is $6 \%$ [88], $6 \%$ for CEA [88,89], and up to $10 \%$ for heart valve replacements [90]. Cardiovascular and cerebrovascular surgery have a negative impact on brain function due to stoppage of blood flow during surgery. In fact, more than $25 \%$ of patients who receive coronary artery bypass surgery suffer from temporary or permanent memory loss. As a result, it is of premier importance to develop strategies to protect the brain either prior to vascular surgeries or in patients at high risk of stroke [38]. A rapid monitoring technique to aid in the detection of ischemic stroke in humans may prove useful in determining a treatment regimen to promote functional recovery.

Although NO is an important regulator of the cerebral circulation, the relative importance of the rapid generation of $\mathrm{NO}$ from nitrite discussed above, as compared to eNOS and nNOS, is unknown. Both eNOS and nNOS are activated somewhat more slowly, in about 10 minutes following ischemia [91]. In a middle cerebral artery (MCA) occlusion model of focal ischemia, nNOS knockout mice develop significantly smaller infarct sizes and have better neurological outcomes

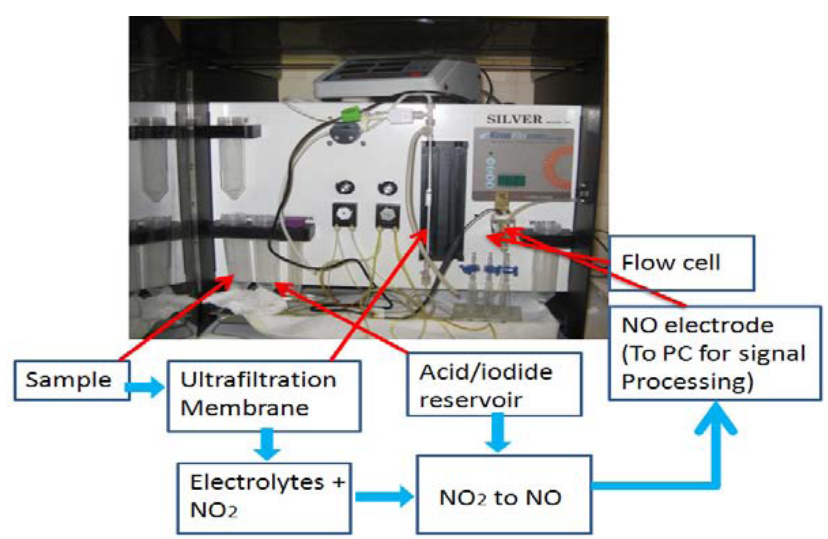

Figure 1: Photograph and block diagram of prototype nitrite detection system. The sample is drawn either from a catheter or from a test tube, and then pumped through an ultrafiltration membrane, where the filtrate is extracted. The filtrate is then mixed with a solution of sulfuric acid and potassium iodide to reduce nitrite $\left(\mathrm{NO}_{2}^{-}\right)$to nitric oxide (NO). The nitric oxide is measured using an NO-specific electrode. Finally, the signal is sent to a PC for readout and signal processing

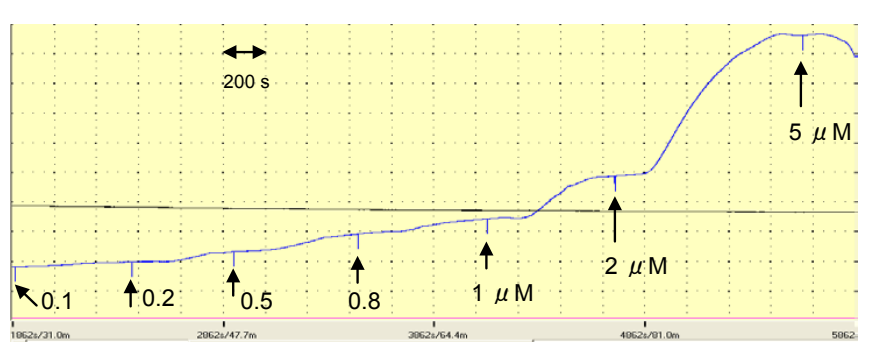

Figure 2: In vitro measurement of $\mathrm{NO}_{2}$ in anticoagulated human blood. In vitro measurement of $\mathrm{NO}_{2}$ in anticoagulated human blood from $100 \mathrm{nM}$ to 5 $\mu \mathrm{M}$. Timescale $200 \mathrm{sec} /$ division. 
Citation: Silver JH (2011) Nitrite and Nitric Oxide as Potential Diagnostic Markers in Acute Vascular Diseases. J Neurol Neurophysiol S1. doi:10.4172/2155-9562.S1-005

than wild-type mice [5]. nNOS knockout mice are also resistant to focal and global cerebral ischemia, consistent with a role for nNOSderived NO in cellular injury following ischemia [5]. In contrast, eNOS knockout mice subjected to the MCA occlusion model develop larger infarct sizes compared to wild-type mice $[5,92]$. Several hours after stroke onset, iNOS is activated as part of the inflammatory processes. The concentrations of NO generated from iNOS are significantly greater than those produced by eNOS and nNOS. In rats, $\mathrm{NO}_{\mathrm{x}}$ rises in jugular venous blood immediately following a stroke induced by middle cerebral artery occlusion and then returns to normal when ischemia is relieved [73]. Clinical research shows that $\mathrm{NO}_{\mathrm{x}}$ is also significantly elevated in cerebrospinal fluid following ischemic stroke [93].

We recently demonstrated the ability to monitor changes in plasma nitrite in real time as an indicator of cerebral ischemia, in a rabbit embolic stroke model [71]. There was a significant increase in plasma nitrite that began immediately following large clot embolization, which reached statistical significance within 3 minutes [71]. This may have occurred due to conversion of intraerythrocytic nitrite to NO, followed by release from red blood cells, followed by rapid oxidation of plasma NO back to plasma nitrite. This would produce at least a transient increase in free nitrite as compared to intracellular nitrite, as measured in this experiment. However, Jeffers et al. [94] provide a theoretical argument that it is not NO which is released from red blood cells during ischemia, but another species, possibly $\mathrm{N}_{2} \mathrm{O}_{3}$, which then decomposes to release $\mathrm{NO}$ outside the cell. Factors favoring the conversion of intracellular (rather than free) nitrite to $\mathrm{NO}$ are the high concentration of intracellular hemoglobin [2] (about $20 \mathrm{mM}$ ), the large fraction of nitrite which is stored within erythrocytes, and the short diffusion distance between intracellular nitrite and deoxyhemoglobin as compared to free nitrite.

Intra-operative monitoring for cerebral ischemia is becoming the standard of care [95]. Even using less sensitive monitoring methods for cerebral ischemia, such as near-infrared spectroscopy (NIRS), EEG, and transcranial Doppler (TCD), clinical researchers have shown dramatic improvements in patient outcomes as compared to unmonitored patients [96-98]. The US Food and Drug Administration recently allowed a label claim that monitoring improves patient outcomes [99]. The therapeutic response for early intra-operative ischemia will primarily involve providing adequate oxygenation to surrounding tissues by elevating the mean arterial pressure, increasing cardiac output or pump flow, altering arterial $\mathrm{CO}_{2}$ tension, or decreasing cerebral oxygen demand using pharmaceutical agents such as propofol, actions that could be managed by the anesthesiologist.

The therapeutic potential of nitrite for stroke was evaluated in a rat model of middle cerebral artery occlusion. In this study, solutions of nitrite were infused intravenously at the time of reperfusion, and were found to reduce infarct volume and enhance local cerebral blood flow and functional recovery. Nitrite treatment was also shown to provide neuroprotection when its administration was delayed to as much as 3 $\mathrm{h}$ following ischemia [4].

\section{Subarachnoid hemorrhage}

Subarachnoid hemorrhage (SAH) is a rare, but particularly devastating, type of stroke produced by a ruptured intracranial aneurysm that affects about 30,000 people annually. While this represents only about $3 \%$ of all strokes and $5 \%$ of deaths from stroke, the relative youth of the affected individuals means that SAH is responsible for a quarter of all life-years lost as a result of stroke [100]. It leads to severe spasm of the cerebral arteries, which develops 4-9 days after SAH in 30-70\% of patients. Of those individuals with delayed cerebral vasospasm, 20-30\% experience delayed ischemic neurological deficits (DIND) and approximately half suffer severe permanent neurological dysfunction or death. The influence of NO on blood flow, the presence of nNOS and eNOS in the cerebral vessels, and the affinity of NO for the heme moiety all suggest that the depletion of NO is responsible for vasospasm [101]. Current research suggests that bilirubin oxidized fragments (BOXes) constrict cerebral arteries by elevating levels of asymmetric dimethyl arginine (ADMA), a competitive inhibitor for NOS enzymes, and thus inhibit basal NO production [102]. This depletion of basal NO levels occurs around the time of vasospasm. Continuous infusions of nitrite have been shown to prevent vasospasm in a primate model of SAH [101]. The ability to monitor nitrite levels either in blood or cerebrospinal fluid on a frequent or continuous basis could provide an extremely rapid indication of the occurrence of vasospasm, and allow much more rapid treatment than the current method - Transcranial Doppler - which is used at most once or twice daily.

\section{Pediatric cerebral ischemia}

More than a half million infants in the US were born preterm in 2004. The preterm birth rate has climbed 18 percent since 1990, to one of every eight live-born infants [103]. Of these children, more than $10 \%$ will sustain neurological injuries leading to significant learning disabilities, cerebral palsy, or mental retardation, with very low birth weight infants having an even higher incidence of brain injury [104]. The estimated lifetime costs in 2003 dollars are expected to total $\$ 51.2$ billion for persons born in 2000 with mental retardation, and $\$ 11.5$ billion for persons with cerebral palsy [105]. No effective clinical strategies have yet been developed to counteract this condition [106]. In addition to preterm infants, the most common birth defect is congenital heart disease (CHD) requiring approximately 36,000 surgeries per year [107]. Improvements in cardiopulmonary bypass (CPB), surgical technique, and intensive care have lowered hospital mortality for most neonatal procedures to $<3 \%$. Improvements in survival have stimulated a focus on neurological morbidity, which may approach $70 \%$ [108].

The two most important forms of brain injury in premature infants, which are believed to be primarily responsible for conditions such as mental retardation, cerebral palsy and epilepsy, are germinal matrix-intraventricular hemorrhage (GMH-IVH) (also known as periventricular-intraventricular hemorrhage (PVIVH)) and periventricular leukomalacia (PVL) [109]. Postnatally, most hemorrhages occur when the neonate is younger than 72 hours, with $50 \%$ of hemorrhages occurring on the first day of life. A large body of experimental and clinical observations indicates that disturbances in cerebral blood flow (CBF) are important in the pathogenesis of PVIVH and PVL. "First, because of their very high incidence of respiratory disease and the need for mechanical ventilation, the complications of such ventilation, alterations in mean arterial blood pressure (MAP) are very common in such infants. Second, considerable experimental data and some clinical results indicate that cerebrovascular autoregulation, the mechanism by which CBF is maintained constant despite alterations in MAP, is either defective or absent in at least some infants" [110]. As with adults, nitric oxide is involved in ischemia in this population as well. Hypoxia-induced release of nitric oxide can account for much of the cerebral vasodilatation observed in response to hypoxia in the fetus [111].

Currently there are no methods for continuously monitoring hypoxic-ischemic insults in the neonatal brain. PVL and PVIVH are 
Citation: Silver JH (2011) Nitrite and Nitric Oxide as Potential Diagnostic Markers in Acute Vascular Diseases. J Neurol Neurophysiol S1. doi:10.4172/2155-9562.S1-005

Page 8 of 13

currently diagnosed using cranial ultrasonography at 7-14 days postnatally, or using MRI, which is more sensitive. However, MRI is not used to assess all infants who may be at risk for PVL. In addition, these methods do not provide continuous monitoring of the patient. "Although non-invasive near infrared spectroscopy (NIRS) has been used for perinatal applications and hundreds of studies have been performed since 1985, it remains very much a developmental technique, despite technical progression. A great deal more research is required for NIRS to become a routine clinical tool" [112].

Potential preventive interventions include avoidance of cerebral ischemia by detection of infants with impaired cerebrovascular autoregulation [113]. Studies estimate a short therapeutic window of 2-6 hours during which interventions may be efficacious in reducing the severity of ultimate brain injury; thus, early identification of a neonate who has sustained a hypoxic-ischemic insult is a paramount objective for optimal management and treatment. Supportive care includes maintenance of adequate ventilation; avoidance of hypotension; maintenance of normal metabolic status including blood glucose, fluid, and nutritional status; control of seizures; and control of brain edema. Recent trials have shown beneficial use of therapeutic hypothermia among infants with hypoxic-ischemic encephalopathy [114]. Blood pressure modification and administration of pharmaceutical agents to decrease oxygen consumption would also be considered.

\section{Acute myocardial infarction}

The long-term prognosis among patients that survive an acute myocardial infarction is based largely on the amount of myocardium that is infarcted as a result of ischemic injury. Therefore, rapid reperfusion of an occluded coronary artery leading to sustained blood flow optimizes outcomes, whereas a delay in restoring blood flow is associated with adverse effects [115]. Significant advances have been made in therapeutic interventions designed to reperfuse occluded arteries during the past several decades. While timely reperfusion of acute ischemic myocardium is essential for myocardial salvage, reperfusion results in a unique form of myocardial damage [4]. Both myocardial stunning and infarction are seen, as well as functional alterations, including depressed contractile function and decreased coronary flow as well as altered vascular reactivity. It has become increasingly clear that oxidant and oxygen radical formation is greatly increased in the post-ischemic heart and serves as a critical central mechanism of post-ischemic injury [115]. Both direct EPR measurements on rapidly frozen tissue and spin trapping measurements have demonstrated that a prominent burst of oxygen radical generation occurs during the early minutes of reperfusion [115]. Therefore, adjunct pharmacotherapies designed to coincide with reperfusion are needed to decrease the extent of reperfusion injury [115].

Nitrite therapy was investigated in a canine model with $2 \mathrm{~h}$ of coronary artery ischemia followed by $6 \mathrm{~h}$ of reperfusion. Nitrite was infused either during the last $60 \mathrm{~min}$ of ischemia or during the last 5 min of ischemia. It was found that nitrite therapy limited myocardial infarction and apoptosis. Importantly, the mechanism of myocardial protection was found to be independent of the area-under-the-curve of the time vs. (severity of ischemia) graph because the group infused with nitrite during the last $5 \mathrm{~min}$ of ischemia experienced a reduction in infarct size and apoptosis to almost a similar degree as the $60 \mathrm{~min}$ infusion group. This suggests that infusion of nitrite could be beneficial if initiated prior to percutaneous coronary intervention [116].

\section{Cardiac arrest}

There are approximately 295,000 cases of out-of-hospital cardiac arrests each year in the US, and an individual's overall chance of surviving until hospital discharge is $7 \%$. The rates of survival to discharge after in-hospital cardiac arrest were $33 \%$ among children and $21 \%$ among adults [117]. Dezfulian et al. [67] showed that global ischemia due to cardiac arrest caused a rapid drop in plasma nitrite levels in mice. They also showed that administration of nitrite solution (as opposed to saline control) at the onset of cardio-pulmonary resuscitation (CPR) following 12 minutes of asystole was cardioprotective. Nitrite therapy significantly improved survival compared with placebo ( $76 \%$ vs. $48 \%$, $\mathrm{p}=0.033$ ). Nitrite therapy also significantly improved post-arrest left ventricular ejection fraction (LVEF) compared with placebo treated mice $(54.4 \pm 2.4 \%$ vs. $43.5 \pm 2.9 \%$; $\mathrm{p}=0.007)$. The investigators found that therapeutic nitrite repletion and S-nitrosation in the heart were associated with transient, reversible inhibition of complex I, reduced mitochondrial reperfusion, ROS generation, and oxidative injury. Nitrite improved pulmonary gas exchange, cardiac contractility, and survival.

\section{Sepsis}

In the United States there are $\sim 750,000$ cases of sepsis or septic shock each year, and that number was expected to have reached 934,000 by 2010 [118]. With a mortality rate of $25-56 \%$ [92], approximately 215,000 patients die each year. In the US, the estimated cost of ICU care for patients with sepsis exceeds $\$ 20$ billion annually [119].

$\mathrm{NO}$ is generally believed to be harmful in sepsis, due to its effects on the macrocirculation (causing arterial hypotension). A phase III multicenter, randomized, double-blind, placebo-controlled trial of the nonspecific NOS inhibitor NG-methyl-L-arginine (L-NMMA) was stopped early because of increased mortality in the NOS inhibition group, which seemed to be caused by cardiac failure [120] even though hypotension was improved [121]. Precisely why this clinical trial failed is not entirely certain, but concerns have been expressed about the dosage, patient selection, titration to maintain blood pressure, as well as the nonspecific nature of the NOS inhibitor used. Despite the lack of benefit of NOS inhibition in this large clinical trial, studies of NO in sepsis continue to yield important pathophysiologic insights.

Sepsis is increasingly recognized as a 'disease of the microcirculation', in which enhanced vasoconstriction and mitochondrial dysfunction cause irreversible damage and organ failure. There are multiple causes of organ failure in sepsis. First, redistribution of blood flow as well as microvascular failure, constriction, obstruction, and permeability changes cause tissue hypoxia and ischemia, which is a failure of oxygen delivery. Second, mitochondrial damage and dysfunction cause metabolic hypoxia which is a failure of oxygen use. Third, reactive oxygen and nitrogen species exert direct cytotoxic effects as well, damaging membranes, lipids, nucleic acids, and proteins [120].

Although inhibition of NOS activity is clearly effective at raising arterial pressure in sepsis, it can simultaneously worsen the impairment of microcirculatory perfusion and oxygen transport to tissues. In the healthy state and under pathologic conditions, NO maintains microcirculatory homeostasis by regulating microvascular tone, leukocyte adhesion, platelet aggregation, microthrombi formation, and microvascular permeability. Blocking NO production in sepsis worsens leukocyte adhesion, platelet aggregation and microthrombosis, and microvascular permeability, causing decreased myocardial blood 
Citation: Silver JH (2011) Nitrite and Nitric Oxide as Potential Diagnostic Markers in Acute Vascular Diseases. J Neurol Neurophysiol S1. doi:10.4172/2155-9562.S1-005

flow and defects in tissue oxygenation that do not recover with fluid resuscitation alone. It has been suggested that vasodilators could be used therapeutically to improve tissue oxygenation in sepsis by opening the microcirculation (arterioles, capillaries, and venules $<100$ mm diameter) [120].

Vasodilation, improvement of peripheral flow, and oxygenation might not be the only solution, as the problem might lie in cellular oxygen utilization rather than in oxygen delivery. Impaired oxygen utilization, also called 'cytopathic' or 'metabolic' hypoxia, is mainly due to reduced activities of mitochondrial respiratory enzyme complexes. Interestingly, mitochondrial dysfunction and reduced concentration or activity of complex I seem to be directly associated with organ failure and mortality in septic patients $[122,123]$. In a study in patients with septic shock, skeletal muscle biopsies demonstrated similar ATP depletion and respiratory chain complex I inhibition [113]. Complex I activity had a significant inverse correlation with norepinephrine requirements (a proxy for shock severity, $\mathrm{p}=0.0003$ ) and nitrite/nitrate concentrations ( $\mathrm{p}=0.0004)$, and a significant positive correlation with concentrations of reduced glutathione $(\mathrm{p}=0.006)$ and $\operatorname{ATP}(p=0.03)$ [122]. In this clinical setting, the degree of mitochondrial dysfunction correlated with the severity of illness and with eventual outcome [122,123]. NO contributes to mitochondrial dysfunction in sepsis, in part by nitrating regulatory proteins. Very high levels of NO can cause opening of the mitochondrial permeability transition pore, with uncoupling of oxidative phosphorylation, dissipation of membrane gradients, membrane swelling, and cell death. This implies that treatments that protect mitochondrial function or stimulate mitochondrial biogenesis and recovery might be useful for preventing organ failure and morbidity in sepsis [120].

The upregulation of inducible nitric oxide synthase (iNOS) in sepsis is heterogeneously expressed between and within organ systems and $\mathrm{NO}$ can be consumed by reactive oxygen species, giving the potential for localized areas of relative NO deficiency in microvascular beds despite a state of excess total body NO. Oxidative stress contributes as well, in which NO-induced mitochondrial injury causes inefficient mitochondrial respiration, with increased production of reactive oxygen and nitrogen species.

\section{Sepsis diagnosis}

While there are clear guidelines as to how physicians should treat septic patients once they are diagnosed [118], making the diagnosis of sepsis is very difficult even among intensivists [124]. The early stage of this disease is known as systemic inflammatory response syndrome (SIRS) and represents an assortment of symptoms, many of which are non-specific, so a diagnosis of SIRS is difficult. As the patient makes the transition from SIRS to sepsis, they are often physically normal, so it is difficult to know when they are making that transition. This is the key stage at which to catch the patients. Currently, sepsis diagnosis is made on the basis of meeting two of four SIRS criteria (including 2 or more of: 1) Temperature $>38^{\circ} \mathrm{C}$ or $<36^{\circ} \mathrm{C}$; 2) Heart rate $>90$ beats/min unless the patient is taking medications to reduce the rate (a beta-blocker or calcium channel blocker) or the heart is paced; 3 ) Respiratory rate $>20$ breaths/min (or $\mathrm{PaCO}_{2}<32$ torr) or mechanically ventilated; 4) Leukocyte count $>12,000 / \mu \mathrm{L}$ or $<4,000 / \mu \mathrm{L}$, or $>10 \%$ immature band forms) as well as low blood pressure, and elevated lactate levels.

Early detection of sepsis can improve patient outcomes by either guiding antibiotic therapy or fluid resuscitative therapy. The association of timely and appropriate antibiotic therapy with improved morbidity and mortality has been established in the ICU setting [125]. Early goal- directed therapy (EGDT) in sepsis and septic shock is now standard of care [126], and is cost-beneficial, as these patients have a shorter length of hospital stay than those receiving standard care [118].

Carrigan et al. [127] provide an excellent review of diagnostic tools for sepsis. "We propose that current diagnostic methods could be complemented by including real time monitoring of proteic biomarkers during the course of treatment. Existing and novel methods alike require a 'wait and see' approach in their diagnostic methods because of their incubation cycles. Although traditional ELISAs (2-3h), immunoluminometric PCT assays (3h), and DNA detection by PCR (5-6h) provide more rapid results than culture testing (24$48 \mathrm{~h}$ ), these methods are incapable of monitoring the exponential changes in biomarkers occurring in both sepsis and experimental in vivo endotoxemia." Further, according to Gao et al. [128], "Current standard microbiological techniques identify infecting organisms after culture of a clinical isolate in conditions suitable for replication of the infectious agent. This may be difficult with fastidious organisms or if patients have received antibiotics. Preliminary classification is usually possible within 24 hours, with full species identification and antimicrobial sensitivity data becoming available 48 to 72 hours after blood sampling. The slowness of the investigation usually mandates the use of 'best guess', and often broad spectrum, antibiotics while awaiting results."

It is widely recognized that an increase in systemic nitric oxide (NO) is a marker for infection. In experimental models of sepsis, NO produced by either eNOS or iNOS begins to increase at $2 \mathrm{hrs}$ following lipopolysaccharide injection, and is maximal at 4-6 hours after initial infection $[129,130]$. iNOS generates much larger quantities of NO than either nNOS or eNOS. $\mathrm{NO}_{\mathrm{x}}$ levels are significantly elevated [131] in patients in the order: septic shock $>>$ sepsis $>$ non-infectious SIRS or normal, healthy controls. $\mathrm{NO}_{\mathrm{x}}$ levels in sepsis and septic shock are also much greater than in other infectious diseases, such as bacterial pneumonia [132]. In one study [133] $\mathrm{NO}_{\mathrm{x}}>54 \mu \mathrm{M}$ showed $87 \%$ sensitivity and $77 \%$ specificity for sepsis. The sensitivity and specificity of $\mathrm{NO}_{\mathrm{x}}$ as a biomarker for sepsis might be dramatically improved by inclusion of kinetic data along with concentration data as part of the diagnostic criteria. In preliminary (unpublished) analysis of the data reported by Spack [133], patients could be identified with sepsis hours or days earlier by inclusion of a kinetics-based criteria such as an increase in $\mathrm{NO}_{2}^{-}>5 \mu \mathrm{M}$ over the preceding measurement, rather than requiring an absolute level to be reached. This could be done by monitoring $\mathrm{NO}_{2}$ - on a much more frequent or potentially continuous basis, which would also dramatically improve the time to diagnosis. In addition, monitoring nitrite continuously might improve the timing at which other biomarkers, such as procalcitonin (PCT) and C-reactive protein (CRP) [127], might also be sampled, thus further improving the sensitivity and specificity of those markers, alone or in combination with $\mathrm{NO}_{2}$. Longer term, earlier identification of sepsis study subjects using $\mathrm{NO}_{2}$, in order to reduce heterogeneity of underlying conditions and disease course would be extremely useful in the identification and validation of new pharmaceutical targets.

\section{Sepsis therapies}

While the current standard of care, EGDT, is not implemented until a drop in blood pressure occurs, development of new therapies are likely to be significantly advanced by earlier detection of changes in NO levels that may ultimately lead to the drop in blood pressure which will allow a diagnosis of sepsis. While recombinant activated protein C (APC, also known as Drotrecogin alpha-activated) is currently the only FDA-approved therapy for sepsis, it is only indicated in patients 
Citation: Silver JH (2011) Nitrite and Nitric Oxide as Potential Diagnostic Markers in Acute Vascular Diseases. J Neurol Neurophysiol S1. doi:10.4172/2155-9562.S1-005

at the late stage of severe sepsis [134]. Ultimately, the most successful therapies will in all probability be those that can be implemented as early as possible.

As discussed above, nitrite has been shown to be an NO donor specifically in conditions of low oxygen tension and low $\mathrm{pH}$, which can be expected in the septic microvasculature. This is important in areas where blood flow should be increased but where NOS-derived and thus oxygen-dependent NO production is compromised [120].Treatment with nitrite has been shown to protect mice against progressive hypothermia, mitochondrial dysfunction, organ damage, and even death induced by a lethal challenge with tumor necrosis factor (TNF) or lipopolysaccharide [135]. Nitrite treatment reduces mitochondrial dysfunction, organ damage, and mortality in shock [120], and thus may be a candidate for the treatment of shock [120]. Nitrite administration could prevent organ damage and multiple organ failure (MOF) by restoring or improving peripheral microvascular perfusion and/or mitochondrial respiration [120].

\section{Summary and future directions}

The potential utility for plasma nitrite as a diagnostic marker is extremely broad, with multiple potential clinical applications, including intra-operative stroke, subarachnoid hemorrhage, cerebral ischemia in premature infants, sepsis, and many others not discussed, such as renal or hepatic ischemia, traumatic brain injury and organ transplantation. Since nitrite levels have been shown to be relatively stable within an individual, the ability to monitor changes may provide an excellent method for diagnosing various diseases. It may be a prognostic indicator of cardiovascular health, similar to cholesterol levels or CRP. Frequent or continuous measurements of nitrite levels may be useful for intra-operative stroke monitoring.

One of the key clinical challenges in the development of nitrite as a diagnostic is that because nitrite and NO are involved in so many biological pathways, the specificity of the marker will be imperfect. The keys to improved specificity will be concentration, kinetics, and location. Gradients between two different sites can help to determine the origins of any changes that are detected. However, in some clinical settings such as cardiovascular surgery, the organs most at risk will be known, and sensitivity will be a key driver. As another example, in pediatric patients, if ischemia is detected and it is not cerebral ischemia, its source would still be identified and treated. Thus, in this setting, sensitivity is far more important than specificity. In settings where specificity is of greater importance, there may be complementary tests that can be used to improve the specificity of the results. For example, testing IL-6 levels will help to confirm whether elevated nitrite levels are due to inflammation. The ability to monitor nitrite levels on a continuous basis will also help to determine the timing of additional tests. Nitrite monitoring is similar to pulse oximetry in that the marker detected is global. Therefore, differential diagnoses will likely be required in the clinical setting to determine the probable cause of changes in nitrite. Chronic inflammatory conditions are likely to show high levels of NO, but are unlikely to show rapid changes, as occurs with ischemia. Sepsis will likely show levels of NO that are much higher than in ischemia.

The therapeutic potential of nitrite as a delivery vehicle for NO under ischemic conditions is considerable. A key requirement for the therapeutic use of nitrite in areas such as stroke, acute myocardial infarction, cardiac arrest, and others discussed above will be the development and validation of appropriate pharmacokinetic and pharmacodynamic models. This will require the ability to make frequent (preferably continuous) measurements of changes in nitrite and nitrate levels in the body. An initial clinical safety study for the continuous infusion of nitrite in healthy volunteers was recently published [28]. Fortunately, the long history of nitrite therapy for treatment of cyanide poisoning provides a substantial clinical safety profile [4]. A pharmacokinetic model [64] of nitrite in healthy volunteers was recently developed. Models of nitrite behavior in disease states such as cerebral ischemia or sepsis may be of significant pharmacologic benefit, so the ability to measure $\mathrm{NO}$ and/or nitrite in real time will help to establish the therapeutic value of nitrite.

The use of nitrite as a therapy for IR injury in humans may have some important limitations [23]. Hypotension due to nitritemediated vasodilation [18] may worsen outcomes in situations where hypoperfusion is already present. The production of NO in the setting of reperfusion may worsen oxidative and nitrosative stress both directly, in a dose-dependent manner [40], or by formation of highly reactive intermediates such as peroxynitrite [136]. It is unclear whether a therapy like nitrite will remain effective in humans with other co-morbidities, such as diabetes mellitus and renal insufficiency, in which biological processes such as eNOS uncoupling could adversely chemically "interact" with nitrite and produce unexpected consequences. Such unexpected effects of the NOS-NO axis has been observed in conditions associated with NO donor therapy and NOS uncoupling $[137,138]$.

Finally, as clinical investigations are initiated for nitrite therapy for indications such as cardiac arrest, sepsis, and acute myocardial infarction, among others, the ability to monitor nitrite in real time has the potential to significantly improve the efficacy of the trials, as titration of nitrite could be performed, unlike with conventional measurement techniques. In addition, real time measurements can help to identify any unexpected problems with nitrite delivery. It remains to be seen whether nitrite monitoring will become a clinical requirement along with nitrite therapies as the results of these investigations become known.

\section{Acknowledgment}

This research was funded in part by a QTDP grant from NIH/IRS and by Silver Medical, Inc.

\section{References}

1. Bredt DS (1999) Endogenous Nitric Oxide Synthesis: Biological Functions and Pathophysiology. Free Rad Res 31: 577-596.

2. Dejam A, Hunter CJ, Pelletier MM, Hsu LL, Machado RF, et al. (2005) Erythrocytes are the major intravascular storage sites of nitrite in human blood Blood 106: 734-739.

3. Lauer T, Preik M, Rassaf T, Strauer B, Deussen A, et al. (2001) Plasma nitrite rather than nitrate reflects regional endothelial nitric oxide synthase activity but lacks intrinsic vasodilator action. Proc Nat Acad Sci 98: 12814-12819.

4. Calvert JW, Lefer DJ (2010) Clinical translation of nitrite therapy for cardiovascular diseases. Nitric Oxide 22: 91-97.

5. Liu VW, Huang PL (2008) Cardiovascular roles of nitric oxide: A review of insights from nitric oxide synthase gene disrupted mice. Cardiovascular Research 77: 19-29.

6. Calvert JW, Lefer DJ (2009) Myocardial protection by nitrite. Cardiovascular Research 83: 195-203.

7. Murad F (2004) Discovery of some of the biological effects of nitric oxide and its role in cell signaling. Biosci Rep 24: 452-474.

8. Lehenkyi V, Zelensky S, Stefanov A (2005) $\mathrm{Ca}^{2+}$-sensitivity and cGMPindependent effects of NO in vascular smooth muscle. Nitric Oxide 12: 105113. 
Citation: Silver JH (2011) Nitrite and Nitric Oxide as Potential Diagnostic Markers in Acute Vascular Diseases. J Neurol Neurophysiol S1. doi:10.4172/2155-9562.S1-005

9. Faraci F, Sobey C (1999) Role of soluble guanylate cyclase in dilator responses of the cerebral microcirculation. Brain Res 821: 368-373.

10. Presta A, Liu J, Sessa W, Stuehr D (1997) Substrate binding and calmodulin binding to endothelial nitric oxide synthase coregulate its enzymatic activity. Nitric Oxide 1: 74-87.

11. Michel J, Feron O, Sacks D, Michel T (1997) Reciprocal regulation of endothelial nitric-oxide synthase by $\mathrm{Ca}$-calmodulin and caveolin. J Biol Chem 272: 15583-15586.

12. Khurana V, Feterik K, Springett M, Eguchi D, Shah V, et al. (2000) Functiona interdependence and colocalization of endothelial nitric oxide synthase and heat shock protein 90 in cerebral arteries. J Cereb Blood Flow Metab 20: 1563-1570.

13. Shin HK, Hong KW (2004) Importance of calcitonin gene-related peptide, adenosine and reactive oxygen species in cerebral autoregulation under normal and diseased conditions. Clin Exp Pharmacol Physiol 31: 1-7.

14. Munzel T, Daiber A, Ullrich V, Mulsch A (2005) Vascular consequences of endothelial nitric oxide synthase uncoupling for the activity and expression of the soluble guanylyl cyclase and the cGMP-dependent protein kinase. Arterioscler Thromb Vasc Biol 25: 1551-1557.

15. Bayir H, Kagan V, Borisenko G, Tyurina Y, Janesko K, et al. (2005) Enhanced oxidative stress in iNOS-deficient mice after traumatic brain injury: support for a neuroprotective role of iNOS. J Cereb Blood Flow Metab 25: 673-684

16. Warner D, Sheng H, Batinic-Haberle I (2004) Oxidants, antioxidants and the ischemic brain. J Exp Biol 207: 3221-3231.

17. Andresen J, Shafi NI, Bryan RM, (2006) Endothelial influences on cerebrovascular tone. J Appl Physiol 100: 318-327.

18. Cosby K, Partovi K, Crawford J, Patel R, Reiter C, et al. (2003) Nitrite reduction to nitric oxide by deoxyhemoglobin vasodilates the human circulation. Nature Medicine 9: 1498-1505.

19. Hill BG, Dranka BP, Bailey SM, Lancaster JR, Darley-Usmar VM (2010) What Part of NO Don't You Understand? Some Answers to the Cardinal Questions in Nitric Oxide Biology. J Biol Chem 285: 19699-19704.

20. Gladwin MT, Schechter AN (2004) NO Contest: Nitrite Versus S-NitrosoHemoglobin. Circ Res 94: 851-855.

21. Shiva S, Sack MN, Greer JJ, Duranski M, Ringwood LA, Burwell, et al. (2007) Nitrite augments tolerance to ischemia/reperfusion injury via the modulation of mitochondrial electron transfer. J Exp Med 204: 2089-2102.

22. Tiso M, Tejero J, Basu S, Azarov I, Wang X, et al. (2011) Human Neuroglobin Functions as a Redox-regulated Nitrite Reductase. J Biol Chem 286: 1827718289.

23. Dezfulian C, Raat N, Shiva S, Gladwin MT (2007) Role of the anion nitrite in ischemia-reperfusion cytoprotection and therapeutics. Cardiovascular Research 75: 327-338.

24. Shiva S (2010) Mitochondria as metabolizers and targets of nitrite. Nitric Oxide 22.

25. Rogers SC, Khalatbari A, Datta BN, Ellery S, Paul V, et al. (2007) NO metabolite flux across the human coronary circulation. Cardiovascular Research 75: 434441

26. Crawford JH, Isbell TS, Huang Z, Shiva S, Chacko BK, et al. (2006) Hypoxia red blood cells, and nitrite regulate NO-dependent hypoxic vasodilation. Blood 107: 566-574.

27. Hollenberg SM, Cinel I (2009) Bench-to-bedside review: Nitric oxide in critical illness - update 2008. Critical Care 13: 218.

28. Pluta R, Oldfield EH, Bakhtian KD, Fathi AR, Smith RK, et al. (2011) Safety and Feasibility of Long-term Intravenous Sodium Nitrite Infusion in Healthy Volunteers. PLoS ONE 6: e14504.

29. Jensen FB, Rohde S (2010) Comparative analysis of nitrite uptake and hemoglobin-nitrite reactions in erythrocytes: sorting out uptake mechanisms and oxygenation dependencies. Am J Physiol Regul Integr Comp Physiol 298 R972-R982.

30. Gladwin MT, Shelhamer JH, Schechter AN, Pease-Fye ME, Waclawiw MA, et al. (2000) Role of circulating nitrite and S-nitrosohemoglobin in the regulation of regional blood flow in humans. Proc Natl Acad Sci 97: 11482-11487.

31. Faassen EEV, Bahrami S, Feelisch M, Hogg N, Kelm M, et al. (2009) Nitrite as regulator of hypoxic signaling in mammalian physiology. Med Res Rev 29: 683-741.
32. Gladwin MT, Raat NJH, Shiva S, Dezfulian C, Hogg N, et al. (2006) Nitrite as a vascular endocrine nitric oxide reservoir that contributes to hypoxic signaling, cytoprotection, and vasodilation. Am J Physiol Heart Circ Physiol 291: H2026H2035.

33. Webb AJ, Patel N, Loukogeorgakis S, Okorie M, Aboud Z, et al (2008) Acute Blood Pressure Lowering, Vasoprotective, and Antiplatelet Properties of Dietary Nitrate via Bioconversion to Nitrite. Hypertension 51: 784-790.

34. Dejam A, Hunter CJ, Tremonti C, Pluta RM, Hon YY, et al. (2007) Nitrite Infusion in Humans and Nonhuman Primates: Endocrine Effects, Pharmacokinetics, and Tolerance Formation. Circulation 116: 1821-1831.

35. Kleinbongard P, Dejam A, Lauer T, Jax T, Kerber S, et al. (2006) Plasma nitrite concentrations reflect the degree of endothelial dysfunction in humans. Free Radical Biology \& Medicine 40: 295-302.

36. Zweier JL, Li H, Samouilov A, Liu X (2010) Mechanisms of Nitrite Reduction to Nitric Oxide in the Heart and Vessel Wall. Nitric Oxide 22: 83-90.

37. Siriussawakul A, Zaky A, Lang J (2010) Role of nitric oxide in hepatic ischemiareperfusion injury. World J Gastroenterol 16: 6079-6086.

38. Shpargel KB, Jalabi W, Jin Y, Dadabayev A, Penn MS, et al. (2008) Preconditioning paradigms and pathways in the brain. Cleveland Clinic $\mathrm{J} \mathrm{Med}$ 75 : S77-S82.

39. Kimura M, Ueda K, Goto C, Jitsuiki D, Nishioka K, et al. (2007) Repetition of Ischemic Preconditioning Augments Endothelium-Dependent Vasodilation in Humans: Role of Endothelium-Derived Nitric Oxide and Endothelial Progenitor Cells. Arterioscler Thromb Vasc Biol 27: 1403-1410.

40. Bolli R (2001) Cardioprotective function of inducible nitric oxide synthase and role of nitric oxide in myocardial ischemia and preconditioning: an overview of a decade of research. J Mol Cell Cardiol 33: 1897-1918.

41. Jones S, Bolli R (2006) The ubiquitous role of nitric oxide in cardioprotection. J Mol Cell Cardiol 40: 16-23.

42. Schulz R, Kelm M, Heusch G (2004) Nitric oxide in myocardial ischemia/ reperfusion injury. Cardiovascular Research 61: 402-413.

43. Alkan T (2009) Neuroprotective Effects of Ischemic Tolerance (Preconditioning) and Postconditioning. Turkish Neurosurgery 19: 406-412.

44. Lochner A, Marais E, Genade S, Isamen BH, Du Toit E, et al. (2009) Protection of the ischaemic heart: investigations into the phenomenon of ischaemic preconditioning. Cardiovasc J Afr 20: 43-51.

45. Hataishi R, Rodrigues A, Neilan T, Morgan J, Buys E, et al. (2006) Inhaled nitric oxide decreases infarction size and improves left ventricular function in a murine model of myocardial ischemia-reperfusion injury. Am J Physiol Heart Circ Physiol 291: H379-384.

46. Hert SGD, Turani F, Mathur S, Stowe DF (2005) Cardioprotection with Volatile Anesthetics: Mechanisms and Clinical Implications. Anesth Analg 100: 1584 1593.

47. Johnson G, Tsao PS, Lefer AM (1991) Cardioprotective effects of authentic nitric oxide in myocardial ischemia with reperfusion. Critical Care Medicine 19 244-252.

48. Loke KE, Laycock SK, Mital S, Wolin MS, Bernstein R, et al. (1999) Nitric Oxide Modulates Mitochondrial Respiration in Failing Human Heart. Circulation 100: 1291-1297.

49. Thomas DD, Liu X, Kantrow SP, Lancaster JRJ (2001) The biological lifetime of nitric oxide: Implications for the perivascular dynamics of $\mathrm{NO}$ and $\mathrm{O}_{2}$. PNAS 98: 355-360.

50. Ma X, Weyrich A, Lefer D, Lefer A (1993) Diminished basal nitric oxide release after myocardial ischemia and reperfusion promotes neutrophil adherence to coronary endothelium. Circ Res 72: 403-412.

51. Calvert J, Lefer D (2006) Statin therapy and myocardial no-reflow. $\mathrm{Br} J$ Pharmacol 149: 229-231.

52. Li J, Bombeck C, Yang S, Kim Y, Billiar T (1999) Nitric oxide suppresses apoptosis via interrupting caspase activation and mitochondrial dysfunction in cultured hepatocytes. J Biol Chem 274: 17325-17333.

53. Ishibashi T, Yoshida J, Nishio M (2003) New Methods to Evaluate Endothelia Function: A Search for a Marker of Nitric Oxide (NO) In Vivo: Re-evaluation of NOx in Plasma and Red Blood Cells and a Trial to Detect Nitrosothiols. Pharmacol Sci 93: 409-416. 
Citation: Silver JH (2011) Nitrite and Nitric Oxide as Potential Diagnostic Markers in Acute Vascular Diseases. J Neurol Neurophysiol S1. doi:10.4172/2155-9562.S1-005

54. Hong H, Sun J, Cai W (2009) Multimodality imaging of nitric oxide and nitric oxide synthases. Free Radical Biology \& Medicine 47: 684-698.

55. Takarada S, Imanishi T, Goto M, Mochizuki S, Ikejima H, et al. (2010) First evaluation of real-time nitric oxide changes in the coronary circulation in patients with non-ischaemic dilated cardiomyopathy using a catheter-type sensor. Eur Heart J 31: 2862-2870.

56. Mochizuki S, Miyasaka T, Goto M, Ogasawara Y, Yada T, et al. (2003) Measurement of acetylcholine-induced endothelium derived nitric oxide in aorta using a newly developed catheter-type nitric oxide sensor. Biochem Biophys Res Comm 306: 505-508.

57. Rysz J, Luciak M, Kedziora J, Błaszczyk J, Sibińska E (1997) Nitric oxide release in the peripheral blood during hemodialysis. Kidney Int 51: 294-300.

58. Brisby H, Ashley H, Diwan AD (2007) In Vivo Measurement of Facet Joint Nitric Oxide in Patients With Chronic Low Back Pain. Spine 32: 1488-1492.

59. Kellogg DL, Zhao JL, Friel C, Roman LJ (2003) Nitric oxide concentration increases in the cutaneous interstitial space during heat stress in humans. $J$ Appl Physiol 94: 1971-1977.

60. Ignarro LJ (2009) Personal communication.

61. Reis GS, Augusto VdS, Souza MEJd, Baldo CF, Rodrigues AJ, (2010) Exhaled breath condensate collection for nitrite dosage. A safe and low cost adaptation. Acta Cirúrgica Brasileira 25: 206-213.

62. Marteus H, Tornberg DC, Weitzberg E, Schedin U, Alving K (2005) Origin of nitrite and nitrate in nasal and exhaled breath condensate and relation to nitric oxide formation. Thorax 60: 219-225.

63. MacArthur PH, Shiva S, Gladwin MT (2007) Measurement of circulating nitrite and S-nitrosothiols by reductive chemiluminescence. J Chromatography B 851 : 93-105.

64. Hon YY, Sun H, Dejam A, Gladwin MT (2010) Characterization of Erythrocytic Uptake and Release and Disposition Pathways of Nitrite, Nitrate, Methemoglobin, and Iron-Nitrosyl Hemoglobin in the Human Circulation. Drug Metabolism and Disposition 38: 1707-1713.

65. Tannenbaum SR (1994) Nitrate and nitrite: origin in humans. Science 205 1333-1335.

66. Ignarro LJ (2007) Personal communication.

67. Dezfulian C, Shiva S, Alekseyenko A, Pendyal A, Beiser DG, et al. (2009) Nitrite Therapy After Cardiac Arrest Reduces Reactive Oxygen Species Generation, Improves Cardiac and Neurological Function, and Enhances Survival via Reversible Inhibition of Mitochondrial Complex I. Circulation 120: 897-905.

68. Gharavi N, El-Kadi A (2003) Measurement of nitric oxide in murine Hepatoma Hepa1c1c7 cells by reversed phase HPLC with fluorescence detection. J Pharm Sci 6: 302-327.

69. Iversen HH, Celsing F, Leone AM, Gustafsson LE, et al. (1997) Nerve-induced release of nitric oxide in the rabbit gastrointestinal tract as measured by in vivo microdialysis. British Journal of Pharmacology 120: 702-706.

70. Ganjali M, Rezapour M, Pourjavid M, Salavati-Niasari M (2003) Highly selective PVC-membrane electrodes based on Co(II)-Salen for determination of nitrite ion. Anal Sci 19: 1127-1131.

71. Silver J, Lapchak P (2011) Continuous Monitoring of Changes in Plasma Nitrite Following Cerebral Ischemia in a Rabbit Embolic Stroke Model. Transl Stroke Res 2: 218-226.

72. Thomas D, Ridnour L, Isenberg J, Flores-Santana W, Switzer C, et al. (2008) The Chemical Biology of Nitric Oxide. Implications in Cellular Signaling. Free Radic Biol Med 45: 18-31.

73. Suzuki M, Tabuchi M, Ikeda M, Tomita T (2002) Concurrent formation of peroxynitrite with the expression of inducible nitric oxide synthase in the brain during middle cerebral artery occlusion and reperfusion in rats. Brain Res 951 : $113-120$

74. Brovkovych V, Dobrucki L, Brovkovych S, Dobrucki I, Kalinowski L, (2001) Nitric Oxide Measurements during Endotoxemia. Clinical Chemistry 47: 1068-1074.

75. Leela Cherian, Goodman JC, Robertson CS (2000) Brain nitric oxide changes after controlled cortical impact injury in rats. J Neurophysiol 83: 2171-2178.

76. Hlatky R, Goodman J, Valadka A, Robertson C (2003) Role of Nitric Oxide in Cerebral Blood Flow Abnormalities after Traumatic Brain Injury. J Cereb Blood Flow Metab 23: 582-588.
77. Heller A (2009) The need for monitoring the actual nitric oxide concentration in tumors. Bioanal Rev 1: 3-6.

78. Tripatara P, Patel N, Webb A, Rathod K, Lecomte F, et al. (2007) Nitrite-derived nitric oxide protects the rat kidney against ischemia/reperfusion injury in vivo: role for xanthine oxidoreductase. J Am Soc Nephrol 18: 570-580.

79. Lloyd-Jones D, Adams R, Carnethon M, De Simone G, Ferguson T, et al. (2009) Heart disease and stroke statistics--2009 update: a report from the American Heart Association Statistics Committee and Stroke Statistics Subcommittee. Circulation 119: 480-486.

80. Ingall T (2004) Stroke--incidence, mortality, morbidity and risk. J Insur Med 36 143-152.

81. Lloyd-Jones D, Adams R, Carnethon M, De Simone G, Ferguson TB, et al. (2009) Heart disease and stroke statistics--2009 update: a report from the American Heart Association Statistics Committee and Stroke Statistics Subcommittee. Circulation Jan 27 119: 480-486.

82. Caro JJ, Huybrechts KF (1999) Stroke Treatment Economic Model (STEM): Predicting Long-Term Costs From Functional Status. Stroke 30: 2574-2579.

83. Moskowitz MA, Lo EH, ladecola C (2010) The science of stroke: mechanisms in search of treatments. Neuron 67: 181-198.

84. Lapchak PA (2010) Translational stroke research using a rabbit embolic stroke model: a correlative analysis hypothesis for novel therapy development. Translational Stroke Research.[Perspective Review] 1: 96-107.

85. The National Institute Of Neurological Disorders And Stroke rtPA Stroke Study Group (1995) Tissue Plasminogen Activator For Acute Ischemic Stroke. N Engl J Med 333: 1581-1587

86. Morris DL, Rosamond W, Madden K, Schultz C, Hamilton S (2000) Prehospital and Emergency Department Delays After Acute Stroke: The Genentech Stroke Presentation Survey. Stroke 31: 2585-2590.

87. Blacker D (2003) In-hospital stroke. Lancet Neurol 2: 741-746.

88. Eagle K, Guyton R, Davidoff R, Ewy G, Fonger J, et al. (1999) ACC/AHA guidelines for coronary artery bypass graft surgery: executive summary and recommendations: a report of the American College of Cardiology/American Heart Association Task Force on Practice Guidelines (Committee to Revise the 1991 Guidelines for Coronary Artery Bypass Graft Surgery). Circulation 100: $1464-1480$

89. Gray W, White H (2002) Carotid stenting and endarterectomy: A clinical and cost comparison of revascularization strategies. Stroke 33: 1063-1070.

90. Bucerius J, Gummert J, Borger M, Walther T, Doll N, (2003) Stroke afte cardiac surgery: a risk factor analysis of 16,184 consecutive adult patients. Ann Thorac Surg 75: 472-478

91. Wei G, Dawson V, Zweier J (1999) Role of neuronal and endothelial nitric oxide synthase in nitric oxide generation in the brain following cerebral ischemia. Biochim Biophys Acta 1455: 23-34.

92. Chen CC, Chong CF, Liu YL, Chen KC, Wang TL (2006) Risk stratification of severe sepsis patients in the Emergency Department. Emerg Med J 23 281-285.

93. Castillo J, Rama R, Davalos A (2000) Nitric Oxide-Related Brain Damage in Acute Ischemic Stroke. Stroke 31: 852-857.

94. Jeffers A, Xu X, Huang KT, Cho M, Hogg N, et al. (2005) Hemoglobin mediated nitrite activation of soluble guanylyl cyclase. Comparative Biochemistry and Physiology, Part A 142: 130-135.

95. Jaffe R (2010) Personal communication.

96. Edmonds H (2005) Protective Effect of Neuromonitoring during Cardiac Surgery. Ann NY Acad Sci 1053: 12-19.

97. Lennard N, Smith J, Dumville J, Abbott R, Evans D, et al. (1997) Prevention of postoperative thrombotic stroke after carotid endarterectomy: the role of transcranial Doppler ultrasound. J Vasc Surg 26: 579-584.

98. Lopez J, Chang S, Steinberg G (1999) The use of electrophysiological monitoring in the intraoperative management of intracranial aneurysms. $J$ Neurol Neurosurg Psychiatry 66: 189-196.

99. ht t p://www.somanetics.com/images/stories/pdfs/ Expandedlabelingrelease041609.pdf

100. Macdonald RL, Pluta RM, Zhang JH (2007) Cerebral vasospasm afte subarachnoid hemorrhage: the emerging revolution. Nature Clinical Practice Neurology 3: 256-263. 
Citation: Silver JH (2011) Nitrite and Nitric Oxide as Potential Diagnostic Markers in Acute Vascular Diseases. J Neurol Neurophysiol S1. doi:10.4172/2155-9562.S1-005

101. Pluta RM, Dejam A, Grimes G, Gladwin MT, Oldfield EH (2005) Nitrite Infusions to Prevent Delayed Cerebral Vasospasm in a Primate Model of Subarachnoid Hemorrhage. JAMA 293: 1477-1484.

102. Pluta RM (2005) Delayed cerebral vasospasm and nitric oxide: review, new hypothesis, and proposed treatment. Pharmacology \& Therapeutics 105: 23-56.

103.http://www.cdc.gov/nchs/data/hestat/prelimbirths04/prelimbirths04health htm\#citation.

104. Back S, Rivkees S (2004) Emerging concepts in periventricular white matter injury. Semin Perinatol 28: 405-414.

105.(2006) Errata: Economic Costs Associated with Mental Retardation, Cerebra Palsy, Hearing Loss, and Vision Impairment --- United States, 2003. MMWR Weekly 55: 881

106. Jensen A, Garnier Y, Middelanis J, Berger R (2003) Perinatal brain damagefrom pathophysiology to prevention. Eur J Obstet Gynecol Reprod Biol 110: S70-S79.

107. Rosamond W, Katherine Flegal, Karen Furie, Alan Go, Kurt Greenlund, et al. (2008) Heart Disease and Stroke Statistics: 2008 Update: A Report From the American Heart Association Statistics Committee and Stroke Statistics Subcommittee. Circulation 117: e25-e146.

108. McQuillen PS, Barkovich AJ, Hamrick SEG, Perez M, Ward P, et al. (2007) Temporal and Anatomic Risk Profile of Brain Injury With Neonatal Repair of Congenital Heart Defects. Stroke 38: 736-741.

109. http://emedicine.medscape.com/article/976654-overview

110. Tsuji M, Saul JP, du Plessis A, Eichenwald E, Sobh J, et al. (2000) Cerebra Intravascular Oxygenation Correlates With Mean Arterial Pressure in Critically III Premature Infants. Pediatrics 106: 625-632.

111. Pearce W (2006) Hypoxic regulation of the fetal cerebral circulation. J Appl Physiol 100: 731-738.

112. Nicklin SE, Hassan I, Wickramasinghe Y, Spencer S (2003) The light stil shines, but not that brightly? The current status of perinatal near infrared spectroscopy. Arch Dis Child Fetal Neonatal Ed 88: F263-F268.

113. Volpe $J$ (2001) Neurobiology of periventricular leukomalacia in the premature infant. Pediatr Res 50: 553-562.

114. Chao CP, Zaleski CG, Patton AC (2006) Neonatal hypoxic-ischemic encephalopathy: multimodality imaging findings. RadioGraphics 26: S159S172.

115. Zweier JL, Hassan Talukder MA (2006) The role of oxidants and free radicals in reperfusion injury. Cardiovascular Research 70: 181-190.

116. Gonzalez FM, Shiva S, Vincent PS, Ringwood LA, Hsu LY, et al. (2008) Nitrite Anion Provides Potent Cytoprotective and Antiapoptotic Effects as Adjunctive Therapy to Reperfusion for Acute Myocardial Infarction. Circulation 117: 2986 2994.

117. Roger VL, Go AS, Lloyd-Jones DM, Adams RJ, Berry JD, et al. (2011) Heart Disease and Stroke Statistics 2011 Update: A Report From the American Heart Association. Circulation 123: e18-e209.

118. Dellinger RP (2008) Surviving Sepsis Campaign: International guidelines for management of severe sepsis and septic shock: Intensive Care Med.

119. http://www.nhlbi.nih.gov/meetings/workshops/bsrts.htm

120. Cauwels A, Brouckaert P (2011) Nitrite regulation of shock. Cardiovascular Research 89: 553-559.

121. López A, Lorente J, Steingrub J, Bakker J, McLuckie A, et al. (2004) Multiplecenter, randomized, placebo-controlled, double-blind study of the nitric oxide synthase inhibitor 546C88: effect on survival in patients with septic shock. Crit Care Med 32: 21-30.

122. Brealey D, Brand M, Hargreaves I, Heales S, Land J, et al. (2002) Association between mitochondrial dysfunction and severity and outcome of septic shock. Lancet 360: 219-223.

123. Svistunenko D, Davies N, Brealey D, Singer M, Cooper C (2006) Mitochondria dysfunction in patients with severe sepsis: an EPR interrogation of individual respiratory chain components. Biochim Biophys Acta 1757: 262-272.

124. Poeze M, Ramsay G, Gerlach H, Rubulotta F, Levy M (2004) An international sepsis survey: a study of doctors' knowledge and perception about sepsis. Critical Care 8: R409-R413.
25. Rivers EP, Mclntyre L, Morro DC, Rivers KK (2005) Early and innovative interventions for severe sepsis and septic shock: taking advantage of a window of opportunity. CMAJ 173: 1054-1065.

126. Rivers E, Nguyen B, Havstad S, Ressler J, Muzzin A, et al. (2001) Early GoalDirected Therapy In The Treatment Of Severe Sepsis And Septic Shock. N Engl J Med 345: 1368-1377.

127. Carrigan SD, Scott G, Tabrizian M (2004) Toward Resolving the Challenges of Sepsis Diagnosis. Clinical Chemistry 50: 1301-1314.

128. Gao H, Evans TW, Finney SJ (2008) Bench-to-bedside review: Sepsis, severe sepsis and septic shock - does the nature of the infecting organism matter? Critical Care 12: 213.

129. Braulio VB, Ten Have GAM, Vissers YLJ, Deutz NEP (2004) Time course of nitric oxide production after endotoxin challenge in mice. Am J Physio Endocrinol Metab 287: E912-E918.

130. Plonka PM, Chlopicki S, Wisniewska M, Plonka BK (2003) Kinetics of increased generation of $\mathrm{NO}$ in endotoxaemic rats as measured by EPR. Acta Biochimica Polonica 50: 807-813.

131. Mitaka C, Hirata Y, Yokoyama K, Wakimoto H, Hirokawa M, et al. (2003) Relationships Of Circulating Nitrite/Nitrate Levels To Severity And Multiple Organ Dysfunction Syndrome In Systemic Inflammatory Response Syndrome. Shock 19: 305-309.

132. Werra Id, Jaccard C, Corradin SB, Chiolero R, Yersin B, et al. (1997) Cytokines, nitrite/nitrate, soluble tumor necrosis factor receptors, and procalcitoninconcentrations: Comparisons in patients with septic shock, cardiogenic shock, and bacterial pneumonia. Critical Care Medicine 25: 607 613.

133. Spack L, Havens PL, Griffith OW (1997) Measurements of total plasma nitrite and nitrate in pediatric patients with the systemic inflammatory response syndrome. Critical Care Medicine 25: 1071-1078.

134. Ulloa L, Brunner M, Ramos L, Deitch EA (2009) Scientific and Clinical Challenges in Sepsis. Curr Pharm Des 15: 1918-1935.

135. Cauwels A, Buys ES, Thoonen R, Geary L, Delanghe J, et al. (2009) Nitrite protects against morbidity and mortality associated with TNF or LPS-induced shock in a soluble guanylate cyclase-dependent manner," J Exp Med 206 2915-2924.

136. Ferdinandy P, Schulz R (2003) Nitric oxide, superoxide, and peroxynitrite in myocardial ischaemia-reperfusion injury and preconditioning. $\mathrm{Br} \mathrm{J}$ Pharmaco 138: 532-43

137. Elrod JW, Duranski MR, Langston W, Greer JJM, Tao L, et al. (2006) eNOS gene therapy exacerbates hepatic ischemia-reperfusion injury in diabetes: a role for eNOS uncoupling. Circ Res 99: 78-85.

138. Takimoto E, Champion HC, Li M, Ren S, Rodriguez ER, et al. (2005) Oxidan stress from nitric oxide synthase- 3 uncoupling stimulates cardiac pathologic remodeling from chronic pressure load. J Clin Invest 115: 1221-1231.

139. Tsuchiya K, Takasugi M, Minakuchi K, Fukuzawa K (1996) Sensitive quantitation of nitric oxide by EPR spectroscopy. Free Radic Biol Med 21: 733-737.

140. Martin U, Bryden K, Devoy M, Howarth P (1996) Increased levels of exhaled nitric oxide during nasal and oral breathing in subjects with seasonal rhinitis. Allergy Clin Immunol 97: 768-772.

141.Zhang X, Broderick M (2000) Amperometric Detection of Nitric Oxide. Mod Asp Immunobiol 1: 160-165. 